\title{
PELATIHAN TEKNOLOGI ASAP CAIR SEKAM PADI SEBAGAI PESTISIDA NABATI DI DESA AIR SATAN KABUPATEN MUSI RAWAS
}

\author{
Fitria Lestari, Ivoni Susanti, Reny Dwi Riastuti \\ Program Studi Pendidikan Biologi, STKIP PGRI Lubuklinggau \\ fitrinq@gmail.com
}

\begin{abstract}
Based on the results of observations and interviews, it is known that farmers in Air Satan Village deal with pests using synthetic pesticides which, if used for a long time, will have an environmental impact. Therefore, one way to reduce these negative impacts is to use liquid smoke from rice husks. Rice husk is a hard layer of rice which generally becomes waste and is not used by the community. To reduce waste from rice husks, it is processed into liquid smoke which can be used to eradicate pests. The method of implementation in this service starts from the socialization stage, the knowledge sharing stage, and the training stage.
\end{abstract}

Keywords:Liquid Smoke, Pests, Rice Husk

\begin{abstract}
Abstrak
Berdasarkan hasil observasi dan wawancara diketahui bahwa petani di Desa Air Satan mengatasi hama menggunakan pestisida sintetis yang jika digunakan dalam waktu lama akan berdampak lingkungan. Oleh karena itu, salah satu cara untuk mengurangi dampak negatif tersebut yaitu menggunakan asap cair sekam padi. Sekam padi merupakan lapisan keras dari padi yang umumnya menjadi limbah dan tidak digunakan oleh masyarakat. Untuk mengurangi limbah dari sekam padi, maka diolah menjadi asap cair yang dapat digunakan untuk membasmi hama. Metode pelaksanaan dalam pengabdian ini dimulai dari tahap sosialisasi, tahap pemberian pengetahuan, dan tahap tahap pemberian pelatihan.
\end{abstract}

Kata Kunci: asap cair, hama, sekam padi

\begin{tabular}{l|l|l} 
Submitted: $2020-09-11$ & Revised: $2020-10-20$ & Accepted: $2020-10-29$
\end{tabular}

\section{Pendahuluan}

Padi merupakan salah satu tanaman pangan yang banyak dibudidayakan oleh petani dan sebagai bahan makanan pokok bagi sebagian besar masyarakat Indonesia (Fitriani, 2016:6). Prediksi permintaan beras 2016-2019 untuk konsumsi langsung diperkirakan masih akan sebesar 124,89 kg/kapita/tahun, dengan pertumbuhan penduduk diasumsikan sebesar $1,20 \%$ pertahun, maka total kebutuhan beras untuk konsumsi langsung rakyat Indonesia pada tahun 2016 sebesar 32,31 juta ton dan sebesar 32,71 juta ton pada tahun 2017 (Heni, 2015:18). Mengatasi kebutuhan padi yang terus meningkat, maka diperlukan upaya keras dalam peningkatan produksi padi baik kualitas maupun kuantitas (Ratih dkk, 2014:19). Terjadinya penurunan produksi padi disebabkan oleh banyak faktor salah satunya yaitu hama (Azwir \& Ridwan, 2009:213). Salah satu kabupaten di Indonesia yang mengalami gagal panen akibat hama, yaitu Kabupaten Musi Rawas.

Wilayah Kabupaten Musi Rawas berada di ketinggian 129 meter DPL terdiri dari $66,5 \%$ dataran rendah yang subur dengan struktur $62,75 \%$ tanah liat. Keadaan alamwilayah Kabupaten Musi Rawas terdiri atas hutan potensial, sawah, ladang, kebun karet, dan kebun lainnya. Di lihat dari sektor pertanian Kabupaten Musi Rawas memiliki 
potensial pertanian yang berupa kawasan persawahan yang terdapat di berbagai wilayah seperti Tugumulyo, Tanah Periuk, Air Satan dan sebagainya (RPJMD Kabupaten Musi Rawas, 2016:3). Laju peningkatan produksi dan produktivitas padi sawah di desa Air Satan selama periode 2008-2012 cenderung turun masing-masing $-0,61 \%$ dan0,11\% dengan rata-rata produksi 862.451 ton dan produktivitas 5,76 ton/Ha. Pada periode 20122016 produksi padi masih cenderung menurun dengan rata-rata produksi 851.332 ton. Pelandaian produksi padi yang terjadi dalam beberapa tahun terakhir diduga disebabkan antara lain oleh degradasi lahan sawah, saluran irigasi, hama dan penyakit. Akan tetapi, penurunan produksi dan produktivitas padi di Desa Air Satan paling dominan disebabkan oleh adanya serangan hama wereng dan walang sangit terhadap pertumbuhan dan perkembangan padi (BPS Kab. Musi Rawas, 2013).

Hasil observasi dan wawancara dengan kelompok tani serta perangkat desa Air Satan diketahui hama yang ditemukan yaitu walang sangit (Leptocorisa acuta), sedangkan jenis-jenis hama yang paling sedikit ditemukan yaitu penggerek batang kuning(Scotinophara coarctata), wereng coklat, kepik coklat (Nezara viridula), hama putih (Nymphula depunctalis guene), orong-orong(Gryllotalpa orientalis), dan lembing hijau (Nezara viridula). Umumnya, untuk menangani masalah hama, petani di Desa Air Satan menggunakan pestisida sintetis. Pestisida sintetis lebih efektif untuk membunuh hama, namun dalam jangka panjang penggunaannya akan berdampak pada keseimbangan ekosistem, selain itu sisa bahan kimia yang terkandung dalam tanaman padi dapat membahayakan kesehatan manusia yang mengkonsumsinya secara terus menerus (Kojong dkk, 2014:2). Oleh karena itu, untuk memperkecil pemakaian pestisida sintetis yang berbahaya, penulis memanfaatkan sekam padi yang hanya dianggap limbah dan diolah menjadi asap cair.

Pemilihan sekam padi sebagai bahan baku asap cair karena tidak mudah terbakar, dan mempunyai ketahanan yang tinggi terhadap penetrasi cairan dan dekomposisi yang disebabkan oleh jamur (Wibowo, dkk., 2008). Sekam padi merupakan lapisan keras yang membungkus kariopsis butir gabah, terdiri dari dua belahan yaitu lemma dan palea yang saling bertautan. Pada proses penggilingan gabah, sekam akan terpisah dari butir beras dan menjadi bahan sisa atau limbah pertanian. Selain itu, berbeda dengan dedak dan bekatul yang masih mempunyai nilai ekonomis dan umumnya dimanfaatkan sebagai pakan ternak atau ikan, sekam dianggap limbah penggilingan padi (Nugraha, 2008). Adanya teknologi sekam cair yang diolah menjadi asap cair ini dapat dijadikan penghasilan tambahan bagi para petani.

Asap cair adalah campuran larutan dari sebaran asap kayu dalam air yang dibuat dengan mengembunkan asap hasil pirolisis kayu. Kualitas dan kuantitas asap cair yang dihasilkan tergantung dari bahan baku jenis dan keras lunaknya kayu yang digunakan. Asap cair terutama mengandung senyawa fenol, benzopiren, dan beberapa asam organik. Asam organik tersebut mempunyai sifat bio-aktivitas sebagai antimikroba dan antioksidan sehingga banyak digunakan dalam industri pengawetan makanan (Wiyantono dan Endang, 2009). Selain itu, pengunaan asap cair untuk membasmi hama lebih ramah lingkungan dan murah di tingkat petani (Putri dkk., 2015)

Berdasarkan hasil observasi di lapangan, berbagai kendala yang dihadapi masyarakat kelompok tani Sukatani di Desa Air Satan Kabupaten Musi Rawas adalah: 1) 
Sekam padi yang tidak dimanfaatkan oleh petani di Desa Air Satan Kabupaten Musi Rawas; 2) Dampak negatif dari penggunaan pestisida sintetis yang digunakan oleh petani untuk mengusir hama padi; dan 3) Kurangnya pengetahuan kelompok tani Sukatani di Desa Air Satan Kabupaten Musi Rawas tentang cara mencegah hama padi dengan memanfaatkan limbah sekam padi yang diolah menjadi asap cair.

Adapun tujuan dari pelaksanaan pengabdian pada masyarakat ini, yaitumenjelaskan kepada masyarakat desa Air Satan tentang mengolah sekam padi menjadi asap cair yang berguna untuk mengurangi hama yang sering mengganggu padi.

\section{Metode}

\section{A. Pelaksanaan Program}

Pelaksanaan pelatihan ini direncanakan pada bulan Agustus s.d Septemberdi Kantor Kepala Desa Air Satan. Peserta pelatihan terdiri dari masyarakat desa yang diwakili oleh kelompok Tani yang akan dibimbing oleh 4 mahasiswa pendamping agar pelatihan berjalan dengan efektif. Kegiatan ini bekerjasama dengan Perangkat Desa sebagai jembatan langsung agar target luaran dapat tercapat secara maksimal.

Adapun pelaksanaan program terdiri dari:

1. Tahap Sosialisasi Program Pelatihan

Pada tahap ini, akan diadakan sosialisasi tentang pemanfaatan sekam padi yang diolah menjadi asap cair sebagai pestisida nabati di Desa Air Satan Kabupaten Musi Rawas.

2. Tahap Pemberian Pengetahuan

Pemberian pengetahuan dasar kepada masyarakat desa yang diwakili penyuluh pertanian mengenai:

a. Memberikan pengetahuan tentang pestisida kimia dan pestisida nabati

b. Memberikan pengetahuan tentang hama penyebab gagal panen

c. Memberikan pengetahuan tentang pemanfaatan limbah sekam padi

d. Memberikan pengetahuan tentang manfaat sekam padi

e. Memberikan pengetahuan tentang asap cair dari sekam padi

f. Memberikan pelatihan tentang cara membuat asap cair dari sekam padi

Kegiatan ini melibatkan narasumber berasal dari dosen-dosen dengan keahlian dibidang masing-masing sehingga dapat saling melengkapi dan berbagi pikiran dan pengetahuan. Pelatihan ini dilaksanakan selama 1 bulan.

\section{Tahap Pemberian Pelatihan}

Setelah masyarakat yang diwakili oleh kelompok tani di Desa Air Satan, tahap selanjutnya adalah pemberian pelatihan tentang pembuatan asap cair dari sekam padi sebagai pestisida nabati di Desa Air Satan Kabupaten Musi Rawas. Sebelum melakukan pelatihan, maka perlu dipersiapkan terlebih dahulu alat dan bahan yang digunakan. Adapun alat yang digunakan adalah drum ukuran 200 liter, pipa besi diameter 1 inci 2 meter, derijen, toples, dan tungku pembakaran. Sedangkan bahan yang digunakan, yaitu sekam padi dan kayu bakar.

Proses persiapan, yaitu: 
1. Membuat lubang pemasukan sekam pada bagian atas drum

2. Membuat lubang pembakaran dibagian bawah drum

3. Pada permukaan atas drum dibuat lubang kemudian di sambung dengan sepotong pipa sepanjang $70 \mathrm{~cm}$ di pasang tegak lurus

4. Pada bagian atas dibuat agak membengkok agar uap yang menyublim tidak kembali ke dalam drum

5. Pada bagian yang bengkok di sambung lagi dengan pipa sepanjang $125 \mathrm{~cm}$ dengan kemiringan bagian bawah $35^{\circ}$.

6. Pada pipa yang tegak lurus, $15 \mathrm{~cm}$ dari permukaan drum dibuatkan bak penampungan air untuk pendingin. Dan alat siap digunakan.

Adapun langkah-langkah proses produksi asap cair sekam padi, yaitu:

1. Memasukkan sekam padi ke dalam drum pembakaran sampah $4 / 5$ bagian melalui lubang pemasukan

2. Menuangkan air pada bak pendingin

3. Memasang botol penampungan asap sekam cair pada pengait yang telah disiapkan

4. Menyalakan/membakar sekam padi dengan kayu bakar dari lubang tungku yang ada dibagian bawah drum yang telah dibuat

5. Menunggu hasil pembakaran selama 3 jam (Gambar 1.)

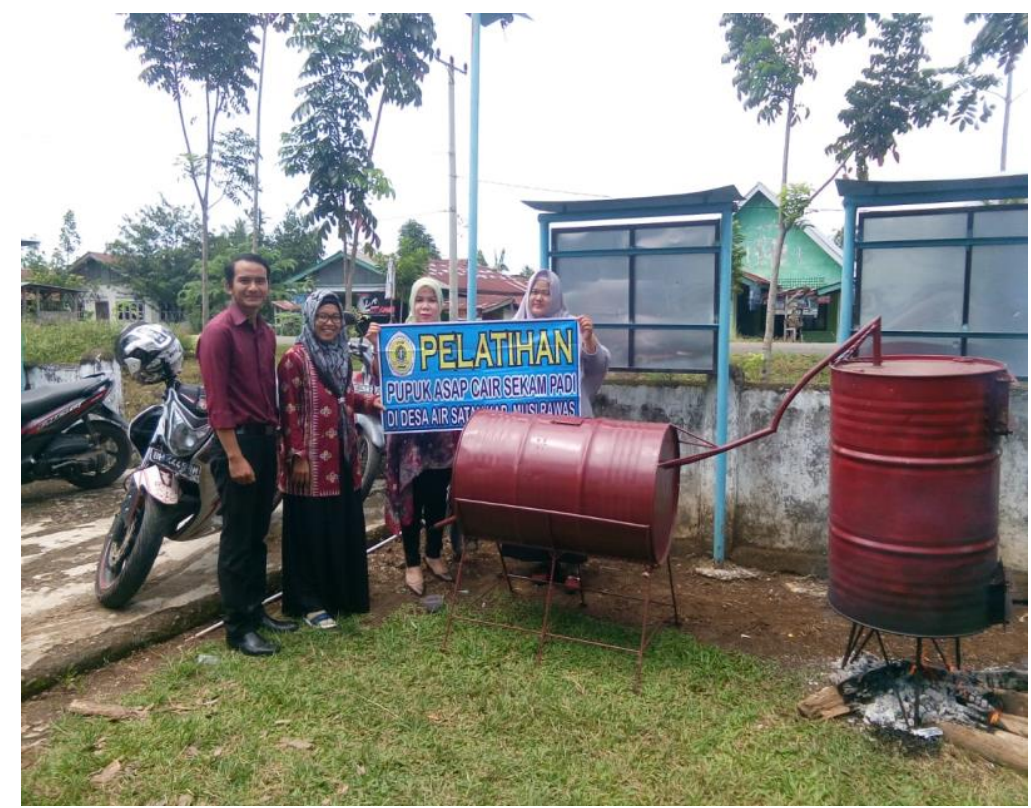

Gambar 1. Alat Pirolisator

4. Tahap Aplikasi Lapangan

Setelah asap cair sekam padi selesai dibuat, maka tahap selanjutnya sebagai berikut:

1. Sebelum digunakan, hasil diendapkan terlebih dahulu selam 7-10 hari untuk menghilangkan dan mengendapkan senyawa tar.

2. Dosisnya $75-100 \mathrm{ml}$ per liter air dengan volume semprot 400-500 liter per hektar.

3. Interval penyemprotan 2- 3 hari sebanyak 5 kali atau disesuaikan dengan tingkat serangan hama. 
4. Penyemprotan dilakukan pagi dan sore hari.

B. Indikator Keberhasilan Program

Indikator keberhasilan program yaitu terampilanya masyarakat dalam membuat asap cair sekam padi.

\section{Hasil dan Pembahasan}

Kegiatan pengabdian Kepada Masyarakat adalah sebuah tugas dan kewajiban seorang dosen untuk menjadi masyarakat memiliki wawasan pengetahuan dan mampu menerapkan teknologi yang sedang berkembang. Semoga dengan kegiatan "Teknologi Asap Sekam Cair Sekam Padi sebagai Pestisida Nabati Di Desa Air Satan Kabupaten Musi Rawas", dapat membuat para kelompok tani terampil dalam memanfaatkan limbah sekam sebagai hasil sampingan dari padi serta memiliki kemampuan dan pengetahuan untuk mengolah limbah sekam padi menjadi asap cair yang dapat digunakan sebagai pengganti pestisida kimia. Kegiatan pelaksanaan PPM dilaksanakan dari tanggal 15-18 November 2018 dengan peserta sebanyak 25 orang dan secara tatap muka dan pelatihan pembuatan asap cair sekam padi.

Pengabdian ini dilaksanakan oleh 3 orang dosen dan 2 orang mahasiswa. Tiga orang dosen memberi materi, yaitu: 1) bahaya pestisida kimia dalam jangka panjang; 2) pemanfaatan limbah sekam pengganti pestisida kimia; 3) pengolahan sekam padi menjadi asap cair; dan 4) Manfaat asap cair.

Hasil kegiatan PPM berjudul "Teknologi Asap Sekam Cair Sekam Padi sebagai Pestisida Nabati Di Desa Air Satan Kabupaten Musi Rawas" secara garis besar mencakup komponen, yaitu: 1) menghasilkan produk berupa alat pengolah asap cair, 2) ketercapaian pemahaman peserta mengenai pemanfaatan limbah sekam, dan 3) ketercapaian penambahan wawasan peserta dalam mengolah sekam menjadi asap cair.

Target jumlah peserta pada kegiatan ini adalah kelompok petani sukatani I dan II yang berjumlah 25 orang dalam pelaksanaannya. Sebelum melaksanakan demonstrasi asap cair sekam padi, terlebih dahulu tim merancang alat untuk mengolah sekam padi menjadi asap cair. Alat tersebut dibuat kurang lebih selama 2 bulan dengan perbaikan rancangan sesuai dengan kebutuhan. Setelah alat selesai, alat tersebut diserahkan kepada ketua Gapoktan yaitu bapak Sudarman dan bapak Ghufron selaku kepala desa Air Satan.

Setelah alat diserahkan, maka langkah selanjutnya adalah menyampaikan materi sebagai pengetahuan awal sebelum demonstrasi dilakukan. Materi yang disampaikan, yaitu: 1) bahaya pestisida kimia dalam jangka panjang; 2) pemanfaatan limbah sekam pengganti pestisida kimia; 3) pengolahan sekam padi menjadi asap cair; dan 4) Manfaat asap cair. Materi yang direncanakan tersebut telah dilaksanakan secara keseluruhan, sehingga materi tuntas. Pada kegiatan pemberian materi, tim PPM melakukan komunikasi secara aktif kepada peserta sehingga respon yang diberikan baik. Setelah materi disampaikan, kegiatan selanjutnya adalah demonstrasi secara langsung cara mengolah sekam padi menjadi asap cair. Adapun tahapannya, yaitu: 1) memasukkan sekam yang telah disedikan ke dalam drum yang telah disediakan, 2) memasukkan air dibagian sisi kedua. Pemberian air bertujuan agar besi penghubung tidak terlalu panas, 3) menghidupkan kayu bakar, 4) tunggu proses selama 3 jam dan menampung asap cair dengan menggunakan derijen. Pada kegiatan 
pengolahan sekam menjadi asap cair ini peserta masih butuh pendampingan karena walaupun materi dan demonstrasi telah dilakukan, tetapi peserta masih belum terlalu paham. Kemudian tim PPM mendampingi dengan mengulang kembali cara mengolah sekam padi menjadi asap cair kepada peserta.

\section{Kesimpulan}

Berdasarkan kegiatan yang telah dilakukan dapat disimpulkan bahwa sekam padi dapat diolah menjadi asap cair yang berpotensi sebagai pestisida nabati.

\section{Daftar Pustaka}

Azwir \& Ridwan. (2009). Peningkatan Produktivitas Padi Sawah dengan Perbaikan Teknologi Budidaya. Balai Pengkajian Teknologi Pertanian Sumatera Barat. Akta Agrosia, 12, (2), 212-218.

Fitiani. (2016). Keanekaragaman Arthropoda Pada Ekosistem Tanaman Padi Dengan Aplikasi Pestisida. Agrovital, 1, (1), 6-8.

Heni, T. (2015). Outlook Komoditas Pertanian Tanaman Pangan Padi. Jakarta: Pusat Data dan System Informasi Pertanian Kementerian Pertanian.

Kojong. H. I., Moulwy. F. D., \& Noni. N. W. (2014). Serangga Predator pada Ekosistem Padi Sawah di Kecamatan Tombatu, Kabupaten Minahasa Tenggara. Fakultas Pertanian Universitas Sam Ratulangi Manado.

Nugraha, S. (2008). Pemanfaatan Sekam sebagai Bahan Bakar Murah. Informasi Ringkas Balai Besar Penelitian dan Bank Pengetahuan Padi Indonesia.

Putri, R.E., Mislaini, dan Lisa, S.N. (2015). Pengembangan Alat Penghisap Asap Cair dari Sekam Padi untuk Menghasilkan Insektisida Organik. Jurnal Teknologi Pertanian. Vol 19 (2)

Ratih, S. I., Sri. K., \& Gatot. M. (2014). Pengaruh Sistem Pengendalian Hama Terpadu dan Konvensional Terhadap Intensitas Serangan Penggerek Batang Padi Musuh Alami pada Tanaman Padi. Program Studi Agroekoteknologi, Jurusan Hama dan Penyakit Tumbuhan, Universitas Brawijaya. Jurnal HPT, 2, (3), 18-27.

Wibowo, H., Muhajir, K., Rusianto,T., dan Arbintarso, E. (2008). Koduktivitas Termal Papan Partikel Sekam Pad. Jurnal Teknologi Technoscientia Vol.1 No. 1. 2630.

Wiyantono dan Endang. (2009). Kajian Potensi Asap Cair dalam Mengendalikan Ulat Crops Kubis (Crocidolomia pavonana). Jurnal Pembangunan Pedesaan. Vol 9(1), 5056 